\title{
Food-dependent exercise-induced anaphylaxis following intake of nuts
}

\author{
Robin George Manappallil'1, Thushara Anand ${ }^{2}$ \\ ${ }^{1}$ Consultant, ${ }^{2}$ Resident, Department of Internal Medicine, Baby Memorial Hospital, Calicut, Kerala, India
}

Allergic reactions can be mild or life threatening. Food-dependent exercise-induced anaphylaxis (FDEIA) is a severe form of allergic reaction in which symptoms develop only after exercising within a few hours of eating a specific food. The condition is, at times, underdiagnosed. Proper history taking is essential, especially when patients present with allergic reactions after exertion following food intake. The patient being described developed FDEIA because of exercising after eating nuts.

Key words: Exercise-induced anaphylaxis; Food-dependent exercise-induced anaphylaxis; Allergic reaction; Anaphylaxis; Nuts; Immunoglobulin E (IgE)
http://nepjol.info/index.php/AJMS DOI: 10.3126ajms.v11i4.28904

E-ISSN: 2091-0576

P-ISSN: 2467-9100

Copyright (c) 2020 Asian Journal of Medical Sciences

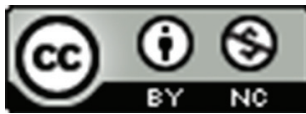

This work is licensed under a Creative Commons Attribution-NonCommercial 4.0 International License.

\section{INTRODUCTION}

Exercise induced anaphylaxis (EIA) accounts for 5-15\% of all cases of anaphylaxis. ${ }^{1}$ Of these, $30 \%$ to $50 \%$ is food dependent. Food-dependent exercise-induced anaphylaxis (FDEIA) is an uncommon form of anaphylaxis that occurs only when the patient exercises within 2 to 4 hours of ingesting a specific food. ${ }^{2}$ Both food intake and exercise are required to trigger off the anaphylaxis. The condition is usually underdiagnosed and gets treated as routine anaphylaxis. A detailed history is essential to establish the diagnosis of FDEIA.

\section{CASE PRESENTATION}

A 22-year-old female came to emergency department with urticarial rash all over the body and dyspnoea. She had presented to a local hospital 2 days ago with similar complaints and was treated with antihistamines and intravenous hydrocortisone, following which she improved. She does not have any food or drug allergies. She did not have any comorbidity and was not on any regular medications.

On presentation, she was conscious, oriented and afebrile. She was having her menses. Her pulse was 100/ minute, blood pressure 100/60 $\mathrm{mm} \mathrm{Hg}$ and respiratory rate 24/ minute with saturation 94\% (in room air). She had bilateral rhonchi. Other systemic examinations were normal. Her blood investigations like complete blood counts, renal and liver parameters, random blood glucose and electrolytes were normal. Electrocardiogram showed sinus tachycardia and chest Xray was normal. Serum IgE levels were $440 \mathrm{IU} / \mathrm{ml}$ (150 and 300). 
She was treated with intravenous hydrocortisone $(100 \mathrm{mg})$ and intramuscular pheniramine maleate $(45.5 \mathrm{mg})$ along with nebulization (salbutamol $2.5 \mathrm{mg}$ + fluticasone $0.5 \mathrm{mg}$ ), following which she improved.

On detailed history, she had changed her diet plan to mainly nuts (peanuts, walnuts, almonds) for lunch and dinner for the past 5 days. However, there was no allergic reaction. She had joined Zumba fitness 2 days ago. She used to eat nuts and then go for Zumba after 2 hours. She had her first episode of allergic reaction during her first day of Zumba session. On presentation to us also, the she had nuts followed by Zumba session. On the basis of her history, FDEIA was suspected as she did not have the allergic reactions on consuming nuts alone, but noticed them when she had nuts followed by Zumba. Food allergy skin prick test was positive for peanut, almond, walnuts and hazelnut. Meanwhile, supervised graded oral challenges for the same at rest were negative. She was discharged on oral levocetrizine (5 mg once daily) for 5 days and advised to avoid physical exercise for at least 4 hours after having food, especially nuts. On 6 months follow up, she did not have any similar episodes.

\section{DISCUSSION}

Maulitz et al., described the first case of FDEIA in 1979 which was triggered by the intake of shellfish prior to exercise. ${ }^{3}$ Unlike EIA, exercise alone cannot trigger the anaphylaxis in FDEIA. In majority of FDEIA patients, immunoglobulin E ( $\mathrm{IgE}$ ) antibodies have been detected against the causative food allergens by skin prick test or radioallergosorbent tests. Hence, FDEIA is believed to be an IgE-mediated hypersensitivity reaction to food allergens. ${ }^{4}$

Clinically, these patients present with symptoms and signs of anaphylaxis following physical exertion within minutes to hours of eating certain foods. These symptoms can occur during any phase of exercise, and even after exercise. ${ }^{5}$ Some of the common food culprits include wheat, shellfish, peanuts, corn and tomatoes. However, a wide variety of other foods have also been implicated. ${ }^{4,6}$ Wheat has been found to be the most common food causing FDEIA among Japanese population because of the omega- 5 gliadin component of wheat gluten., ${ }^{7,8}$ Sometimes the ingestion of two foods together along with exercise are required to trigger an anaphylactic reaction. ${ }^{9}$ Drugs like aspirin and NSAIDs, dust and pollen, hot and humid climate, stress and menses can act as contributing factors. ${ }^{10-12}$
Several theories have been suggested with regard to the pathogenesis of FDEIA. One is the activation of the intestinal enzyme tissue transglutaminase during exercise which is capable of binding and aggregating gliadin moieties to form large immunogenic complexes. ${ }^{8}$ Another suggestion was the increased gastric permeability which occurs during exercise; resulting in increased entry of intact or incompletely digested allergens into the circulation. This scenario does not occur at rest. ${ }^{10} \mathrm{~A}$ third theory described that during exercise there is redistribution of blood away from the viscera to the skin and musculature. This results in transport of food allergens to tissues containing mast cells, leading to an allergic reaction. ${ }^{13} \mathrm{~A}$ fourth theory proposed that during exercise there is mobilization and activation of immune cells from gut-associated depots, which stimulates pro-inflammatory responses. ${ }^{14}$

The diagnosis of FDEIA is usually made on the basis of detailed history of events surrounding the episodes and clinical presentation. The demonstration of food-specific $\operatorname{IgE}$ by skin testing or in vitro assays is essential to identify the precipitating food(s). ${ }^{15}$ The diagnosis is confirmed by a positive food and exercise challenge; however, a negative result does not essentially exclude FDEIA. The Standard Bruce protocol of exercise treadmill test has been used with variable success. ${ }^{4,16}$ The Gold standard for the diagnosis of FDEIA is a 3-day challenge test. ${ }^{17} \mathrm{~A}$ retrospective study from Sri Lanka used the following diagnostic criteria: $3,5,18,19$

- Clinical diagnosis of anaphylaxis as outlined by World Allergy Organization (WAO) criteria $^{18}$

- Onset of symptoms during exertion with ingestion of the implicated food within 4 hours

- Ability to eat the implicated food independent of exercise, or ability to exercise safely if the food was not ingested in the preceding 4 hours

- Evidence of sensitivity to the food by in vitro (ImmunoCap serum IgE to the implicated food) or in vivo (skin prick test).

The management of FDEIA is mainly by prevention of such attacks by avoiding physical exertion for at least 4 hours following intake of the precipitating foods. Other measures include reducing the intensity of exercise, avoiding exercise in extreme weathers such as hot and humid or cold temperatures and carrying an epinephrine autoinjector during exercise. ${ }^{20}$ The treatment involves routine anaphylaxis medications like epinephrine, antihistamine, bronchodilators and hydrocortisone. Taking antihistamines or $\mathrm{H} 2$ blockers prior to exercise is controversial. ${ }^{5,21}$ The recombinant DNA monoclonal antibody, omalizumab, which binds to $\operatorname{IgE}$ and neutralises its activity in type I allergic reactions has been successfully tried as prophylaxis 
in refractory FDEIA. ${ }^{22}$ The administration of prostaglandin E1 analogue misoprostol prior to exercise has shown to decrease wheat-dependent anaphylaxis, probably due to upregulation of gastrointestinal breakdown of allergic particles. ${ }^{23}$

Only a handful of cases of FDEIA have been reported. ${ }^{6,22-24}$ Our patient had FDEIA due to intake of nuts prior to Zumba sessions. Moreover, she was having her menses which could have acted as a contributory factor.

\section{CONCLUSION}

FDEIA is an uncommon condition and remains underdiagnosed, probably because of lack of awareness. These patients present with recurrent unexplained allergic reactions and get routine anaphylaxis treatment. A proper history will aid to establish the diagnosis. With proper advice, that is to avoid exercise following ingestion of the culprit food item will help to prevent such allergic reactions.

\section{REFERENCES}

1. Du Toit G. Food-dependent exercise-induced anaphylaxis in childhood. Pediatr Allergy Immunol 18:455-463.

https://doi.org/10.1111/j.1399-3038.2007.00599.x

2. Sampson HA, Burks AW. Adverse reactions to foods. In: Adkinson NF, Yunginger JW, Buss WW, editors. Middleton's Allergy: Principles and Practice. 7th ed. Maryland Heights: Mosby; 2008. p. 1156.

3. Maulitz RM, Pratt DS and Schocket AL. Exercise-induced anaphylactic reaction to shellfish. J Allergy Clin Immunol 1979;63:433-434.

https://doi.org/10.1016/0091-6749(79)90218-5

4. Romano A, Di Fonso M, Giuffreda F, Papa G, Artesani MC, Viola $\mathrm{M}$, et al. Food-dependent exercise-induced anaphylaxis: Clinical and laboratory findings in 54 subjects. Int Arch Allergy Immunol 2001; 125:264-272.

https://doi.org/10.1159/000053825

5. Barg W, Medrala W and Wolanczyk-Medrala A. Exerciseinduced anaphylaxis: an update on diagnosis and treatment. Curr Allergy Asthma Rep 2011;11:45-51.

https://doi.org/10.1007/s11882-010-0150-y

6. Al-Nesf MA and Mobayed HM. Two cases of food-dependent exercise-induced anaphylaxis with different culprit foods. Ann Thorac Med 2014; 9:42-44.

https://doi.org/10.4103/1817-1737.124443

7. Morita E, Kunie $\mathrm{K}$ and Matsuo $\mathrm{H}$. Food-dependent exerciseinduced anaphylaxis. J Dermatol Sci 2007; 47:109-117. https://doi.org/10.1016/j.jdermsci.2007.03.004

8. Palosuo K, Varjonen E, Kekki OM, Klemola T, Kalkkinen N, Alenius $\mathrm{H}$, et al. Wheat omega- 5 gliadin is a major allergen in children with immediate allergy to ingested wheat. J Allergy Clin Immunol 2001; 108: 634-638.

https://doi.org/10.1067/mai.2001.118602

9. Povesi Dascola C and Caffarelli C. Exercise-induced anaphylaxis: a clinical view. Ital J Pediatr 2012;38:43.

https://doi.org/10.1186/1824-7288-38-43

10. Matsuo H, Morimoto K, Akaki T, Kaneko S, Kusatake K, Kuroda T, et al. Exercise and aspirin increase levels of circulating gliadin peptides in patients with wheat-dependent exercise-induced anaphylaxis. Clin Exp Allergy 2005; 35:461-466. https://doi.org/10.1111/j.1365-2222.2005.02213.x

11. Shadick NA, Liang MH, Partridge AJ, Bingham C, Wright E, Fossel $\mathrm{AH}$, et al. The natural history of exercise-induced anaphylaxis: Survey results from a 10-year follow-up study. J Allergy Clin Immunol 1999; 104:123-127. https://doi.org/10.1016/S0091-6749(99)70123-5

12. Bito $T$, Kanda $E$, Tanaka M, Fukunaga A, Horikawa $T$ and Nishigori C. Cow's milk-dependent exercise-induced anaphylaxis under the condition of a premenstrual or ovulatory phase following skin sensitization. Allergol Int 2008; 57:437-439. https://doi.org/10.2332/allergolint.C-08-62

13. Robson-Ansley $P$ and Toit GD. Pathophysiology, diagnosis and management of exercise-induced anaphylaxis. Curr Opin Allergy Clin Immunol 2010; 10:312-317. https://doi.org/10.1097/ACl.0b013e32833b9bb0

14. Cooper DM, Radom-Aizik S, Schwindt $C$ and Zaldivar F Jr. Dangerous exercise: Lessons learned from dysregulated inflammatory responses to physical activity. J Appl Physiol 2007; 103:700-709. https://doi.org/10.1152/japplphysiol.00225.2007

15. Wong CG and Mace SR. Food-dependent exercise-induced anaphylaxis: A case related to chickpea ingestion and review. Allergy Asthma Clin Immunol 2007; 3:134-137. https://doi.org/10.1186/1710-1492-3-4-134

16. Aihara M, Miyazawa M, Osuna H, Tsubaki K, Ikebe T, Aihara $Y$, et al. Food-dependent exercise-induced anaphylaxis: Influence of concurrent aspirin administration on skin testing and provocation. Br J Dermatol 2002; 146:466-472. https://doi.org/10.1046/j.1365-2133.2002.04601.x

17. Pacharn $P$, Jirapongsananuruk $O$, Daengsuwan $T$, Vichyanond $P$, Visitsunthorn N. Wheat-dependent, exercise-induced anaphylaxis in Thai children: a report of 5 cases. Asian Pac J Allergy Immunol 2009;27:115-120.

18. Muraro A, Roberts G, Worm M, Bil MB, Brockow K, Fernández Rivas $M$, et al. Anaphylaxis: guidelines from the European Academy of Allergy and Clinical Immunology. Allergy 2014; 69:1026-1045.

https://doi.org/10.1111/all.12437

19. de Silva NR, Dasanayake WM, Karunatilleke C and Malavige GN. Food dependant exercise induced anaphylaxis a retrospective study from 2 allergy clinics in Colombo, Sri Lanka. Allergy Asthma Clin Immunol 2015;11(1):22. https://doi.org/10.1186/s13223-015-0089-6

20. Soyer OU and Sekerel BE. Food dependent exercise induced anaphylaxis or exercise induced anaphylaxis? Allergol Immunopathol (Madr) 2008;36(4):242-243. https://doi.org/10.1157/13127050

21. Castells MC, Horan RF and Sheffer AL. Exercise induced anaphylaxis. Curr Allergy Asthma Rep 2003;3(1):15-21. https://doi.org/10.1007/s11882-003-0005-x

22. Bray SM, Fajit ML and Petrov AA. Successful treatment of exercise-induced anaphylaxis with omalizumab. Ann Allergy Asthma Immunol 2012;109(4):281-282. https://doi.org/10.1016/j.anai.2012.07.021 
23. Takahashi A, Nakajima K, Ikeda M, Sano S, Kohno K and Morita E. Pre-treatment with misoprostol prevents food-dependent exerciseinduced anaphylaxis (FDEIA). Int J Dermatol 2011;50(2):237-238 https://doi.org/10.1111/j.1365-4632.2010.04314.x

24. Minty B. Food-dependent exercise-induced anaphylaxis. Can Fam Physician. 2017;63(1):42-43.

Authors Contribution:

RGM- Concept and design, manuscript preparation, revision of manuscript and treating Physician; TA- Resident in-charge.

Work attributed to:

Department of Internal Medicine, Baby Memorial Hospital, Calicut, Kerala, India.

Orcid ID:

Dr. Robin George Manappallil - (i) http://orcid.org/0000-0003-3973-6800

Source of support: None, Conflicts of Interest: None 